\title{
A role for angiogenesis in rheumatoid arthritis
}

\author{
D.G. Stupack, \\ C.M. Storgard \\ and D.A. Cheresh
}

Departments of Immunology and Vascular Biology,

The Scripps Research Institute, La Jolla, CA, USA

\section{Correspondence \\ D.A. Cheresh \\ The Scripps Research Institute \\ IMM 24 \\ 10550 N. Torrey Pines Rd. \\ La Jolla, CA 92037 \\ USA \\ Fax: + 1-619-784-8926 \\ E-mail: cheresh@scripps.edu}

Presented at the 5th Brazilian Symposium on Extracellular Matrix - SIM EC, Angra dos Reis,

RJ, Brasil, September 7-10, 1998.

Research supported in part by the Jeanette $\mathrm{Hennings} \mathrm{Foundation} \mathrm{and}$ NIH (Nos. CA50286, CA 45726 and HL54444). D.G. Stupack and C.M. Storgard are recipients of fellowships from the Joseph Drown Foundation and the Arthritis Foundation, respectively.

Received October 19, 1998 Accepted November 12, 1998

\begin{abstract}
Rheumatoid arthritis (RA) is a chronic debilitating disease characterized by distinct autoimmune, inflammatory and fibrovascular components which lead to synovial proliferation and joint destruction. However, existing treatments specifically target only autoimmune and inflammatory components despite the fact that neovascularization of the inflamed synovium is a hallmark of rheumatoid arthritis. Angiogenesis may contribute to synovial growth, leukocyte recruitment and tissue remodeling, thus potentiating disease progression. Although no therapies currently target angiogenesis, several existing therapies have anti-angiogenic activity. Recent advances in anti-angiogenic strategies in oncology, including the identification of integrin $\alpha v \beta 3$ as a crucial effector of angiogenesis, suggest a means to assess the role of angiogenesis in rheumatoid arthritis. Synovial endothelial cells have been shown to express integrin $\alpha v \beta 3$, suggesting that these cells may be targeted for angiogenesis inhibition. Prior studies in rat arthritis models have shown benefit after the addition of broad spectrum integrin antagonists. However, formal assessment of integrin-targeted anti-angiogenic activity is now underway. These controlled studies will be important in assessing the efficacy of therapies which target angiogenesis in RA.
\end{abstract}

\section{Introduction}

Rheumatoid arthritis (RA) is a complex chronic inflammatory disease which affects approximately $1-3 \%$ of the general population. The disease has several complementary yet distinct components, including autoimmune, inflammatory and fibrovascular responses, which contribute to the significant morbidity and mortality associated with advanced disease $(1,2)$. Currently, a conclusive etiology is lacking, but after an initiating insult, autoimmunity is triggered in a genetically predisposed individual. The resultant articular pathology is characterized by inflammation and proliferation of the synovial lining, resulting in the generation of interdigitating folds of tissue, termed pannus (3). The pannus is a major site of ongoing inflammation and protease production, and is thought to be central to the development of cartilage and bone-erosive disease which leads to the destruction of joint architecture (3-5).

A variety of anti-inflammatory and immunosuppressive regimens have been employed to limit disease. However, significant toxicity is associated with current therapies 
which subdue but ultimately fail to stop progression to erosive joint destruction. Clearly, further modes of intervention for RA are needed. In this regard, the extensive synovial neovasculature, which is one of the earliest histopathologic findings and a hallmark of RA $(6,7)$, has been suggested as an attractive target for therapy. Importantly, many of the therapies currently in use including gold (8), sulfonamides (9), chloroquine (10), methotrexate (11), penicillamine (12), and COX inhibitors (13) have retrospectively been found to possess anti-angiogenic activity either in vivo or in vitro. However, previous examination of angiogenesis inhibition as a primary therapeutic approach in RA is limited $(14,15)$, and presently there are no drugs specifically targeted at preventing the subsynovial vascularization which characterizes this disease.

\section{Angiogenesis as a propagating factor in RA}

Angiogenesis, the coordinated growth of new blood vessels from pre-existing vasculature, occurs physiologically during reproductive and developmental processes as well as during the late phases of wound healing following tissue damage. However, inappropriate or aberrant angiogenesis is associated with a variety of diseases, including tumor growth and metastasis as well as fibrovascular disorders such as psoriasis, diabetic retinopathy and RA (16). In fact, the invasive growth of pannus tissue in RA has been compared to that of neoplastic tumors, and it has been suggested that the pannus itself may be considered a form of benign tumor (17). The recent successes of anti-angiogenic therapies in controlling tumor growth provide a strong rationale to investigate these agents as potential new strategies to limit pannus growth and joint destruction in RA.

Angiogenesis has been suggested to be central to the pathophysiology of RA, contributing to disease progression at multiple levels $(6,7)$. The most obvious role of vascularization during RA is an increased capacity to sustain the nutritional and metabolic requirements of the hyperproliferating synovium and invading pannus (3-5). However, it is clear that the neovascularization which is ultimately achieved is not completely sufficient to relieve the intra-articular hypoxia associated with RA (18), resulting in a chronic angiogenic response.

In part, this is likely due to the distinction that in RA angiogenesis occurs within the context of an ongoing autoimmune reaction, where leukocyte extravasation into the tissues serves to maintain a local inflammatory response. Neovascularization, and the resulting increased vascular bed volume, directly permit increased recruitment of bloodborne leukocytes into the synovial tissue. In turn, these activated leukocytes release angiogenic cytokines (see below) but also cause local microvascular occlusion and injury. Further damage to endothelial cells occurs directly via the release of high levels of reactive oxygen species and proteolytic enzymes (19). In turn, local vessel damage will subsequently induce a reparative angiogenic response from adjacent or contiguous vessels. Thus, the synovial vasculature is not static, but undergoes dynamic reorganization in response to cumulative cycles of endothelial proliferation and death (18).

\section{A direct role for endothelial cells in articular remodeling}

Recent investigations have revealed that activated endothelial cells may make direct contributions to both ongoing inflammation and protease production. The increased endothelial mass in RA can function as a rich source of inflammatory cytokines including IL-1, IL-6 and IL-8, as well as both vascular endothelial cell growth factor (VEGF) and basic fibroblast growth factor (bFGF) (reviewed in 6,7). Importantly, many of these cytokines produced are themselves angio- 
genic, providing a direct autocrine mechanism to sustain neovascularization of the subsynovial tissue (20). Alternatively, many cytokines present in synovial tissues play an indirect role in neovascularization by stimulating the secretion of directly angiogenic cytokines from either inflammatory or bystander cell populations, while selected cytokines have both activities (Table 1). For example, in addition to angiogenic effects on endothelial cells, the production of VEGF and bFGF also serves to activate cells of the macrophage (21) and fibroblast (22) lineages, respectively. Interestingly, these two lineages are the predominant components of the hyperproliferative synovial lining, and comprise a significant proportion of the pannus in RA.

Early responses of the endothelium to angiogenic cytokines include the initiation of vascular permeability and subsequently the upregulation of protease production. These events result in significant alteration of the composition of the local extracellular matrix (ECM). Numerous proteases including urokinase, tissue plasminogen activator and the metalloproteinases MMP-1, 2, 3, and 9 are produced by activated endothelial cells $(5-8,23)$. The metalloproteinases are capable of digesting subendothelial base- ment matrix, particularly collagen types IV and $\mathrm{V}$, which act to suppress the angiogenic phenotype $(14,24,25)$. The combined proteolysis and vascular permeability not only eliminates the capacity of these collagens to inhibit angiogenesis, but additionally provides a new provisional ECM to sustain endothelial survival (26) and migration (27). Plasma glycoproteins including fibrinogen and fibronectin polymerize extravascularly (28) and probably also on the luminal face of the endothelium (29), similar to normal wound healing responses. However, unlike wound healing, the deposited "provisional" matrix is not effectively remodeled and replaced in RA. In fact, evidence suggests that the deposition of this provisional ECM is sustained (30,31), and actually contributes to arthritic disease severity (31).

In this respect, components of the provisional ECM are potent cell activators. Fibronectin, vitronectin and fibrinogen can be chemotactic or haptotactic substrates for endothelial cells (32-35). The principal receptors involved in endothelial attachment to, and migration on, these substrates are integrins, a family of heterodimeric $(\alpha / \beta)$ transmembrane adhesion receptors (36). Although the integrins have no intrinsic kinase activity, it has become clear that integrin-

Table 1 - Selected angiogenic cytokines present in RA.

\begin{tabular}{|c|c|c|c|c|}
\hline Cytokine & $\begin{array}{l}\text { Production } \\
\text { by endothelium }\end{array}$ & $\begin{array}{l}\text { Direct effects } \\
\text { on endothelium }\end{array}$ & $\begin{array}{l}\text { Other target } \\
\text { cells in RA }\end{array}$ & References \\
\hline bFGF & Yes & Angiogenic & Synovial fibroblasts & $6,7,21$ \\
\hline VEGF & Yes & Angiogenic & Macrophage & $6,7,22,58,59$ \\
\hline IL-1 & No & Chemotactic, indirectly angiogenic & Leukocytes & $6,7,57,58,59,60$ \\
\hline IL-6 & Yes & Indirectly angiogenic & Leukocytes & $6,7,10,58$ \\
\hline IL-8 & Yes & Angiogenic & Leukocytes & $6,7,58$ \\
\hline TNF- $\alpha$ & No & Toxic, indirectly angiogenic & Leukocytes & $6,7,57,58,60$ \\
\hline EGF, TGF- $\alpha$ & No & Angiogenic & Fibroblasts, smooth muscle cells & $6,7,58$ \\
\hline PDGF & Yes & Angiogenic & Fibroblasts, smooth muscle cells & $6,7,58$ \\
\hline HGF & No & Chemotactic (angiogenic) & Selected leukocytes & 7,61 \\
\hline
\end{tabular}


mediated adhesion events are sufficient to activate cellular signaling through a variety of nonreceptor tyrosine, serine/threonine and lipid kinases (36). In leukocytes, integrinmediated interaction with provisional ECM proteins can facilitate mitogenic, chemotactic and oxidative responses, depending upon the specific subpopulation of cells studied (36-39). Integrin-mediated signaling also provides a crucial mechanism for adhesiondependent survival in endothelial cells and fibroblasts (36). The importance of this integrin-mediated event is demonstrated by the observation that starved, but adherent endothelial cells, resist apoptosis better than starved or growth factor-stimulated cells maintained in suspension (26). Moreover, recent investigations show that endothelial cell signaling events elicited by angiogenic growth factors, including activation of the downstream effector MAP kinase, are dramatically augmented in vitro and in vivo by integrin-mediated interactions with the ECM $(40,41)$.

\section{Vascular integrin $\alpha \mathrm{V} ß 3$ in angiogenesis}

Integrin $\alpha v b 3$ has recently been characterized as a marker of angiogenic endothelium and as a central effector of this process (42). It is clear that ECM composition plays a determining role in endothelial cell responses, and in this respect integrin $\alpha v \beta 3$ is known to be a receptor for a variety of ECM proteins, including denatured collagen, fibronectin, fibrinogen and vitronectin (43). Further, $\alpha v \beta 3$ can bind to the metalloproteinase MMP-2, localizing it to the endothelial cell surface and subsequently potentiating its activation from precursor zymogen to active enzyme (44). Therefore, expression of integrin $\alpha v \beta 3$ expands the range of ligands which endothelial cells can interact with and also modifies cellular interactions with preexisting ligands.

Inhibition of integrin ligation by selective antagonists not only blocks the migration of endothelial cells stimulated by angio-
Figure 1 - Potential mechanisms of angiogenesis inhibition by antagonists of integrin $\alpha \mathrm{V} ß 3$. Angiogenic growth factors induce vascular permeability, provisional extracellular matrix (ECM) deposition, degradation of the subendothelial basement matrix proteins and expression of integrin $\alpha \mathrm{VB3}$. The presence of antagonists of integrin $\alpha \mathrm{V} ß 3$ may prevent angiogenesis by blocking migratory or invasive processes associated with endothelial sprouts, thus limiting endothelial penetration to target areas. However, antagonists of integrin $\alpha \mathrm{VB3}$ can also block ECMdependent cell survival signals (grey arrows), including activation of NF-kB and suppression of p53-mediated transcription of the apoptosis-inducing genes bax and p21waf. Blockade of these survival signals (black $X$ ) can result in the onset of programmed cell death and the local disruption of angiogenic vessels.

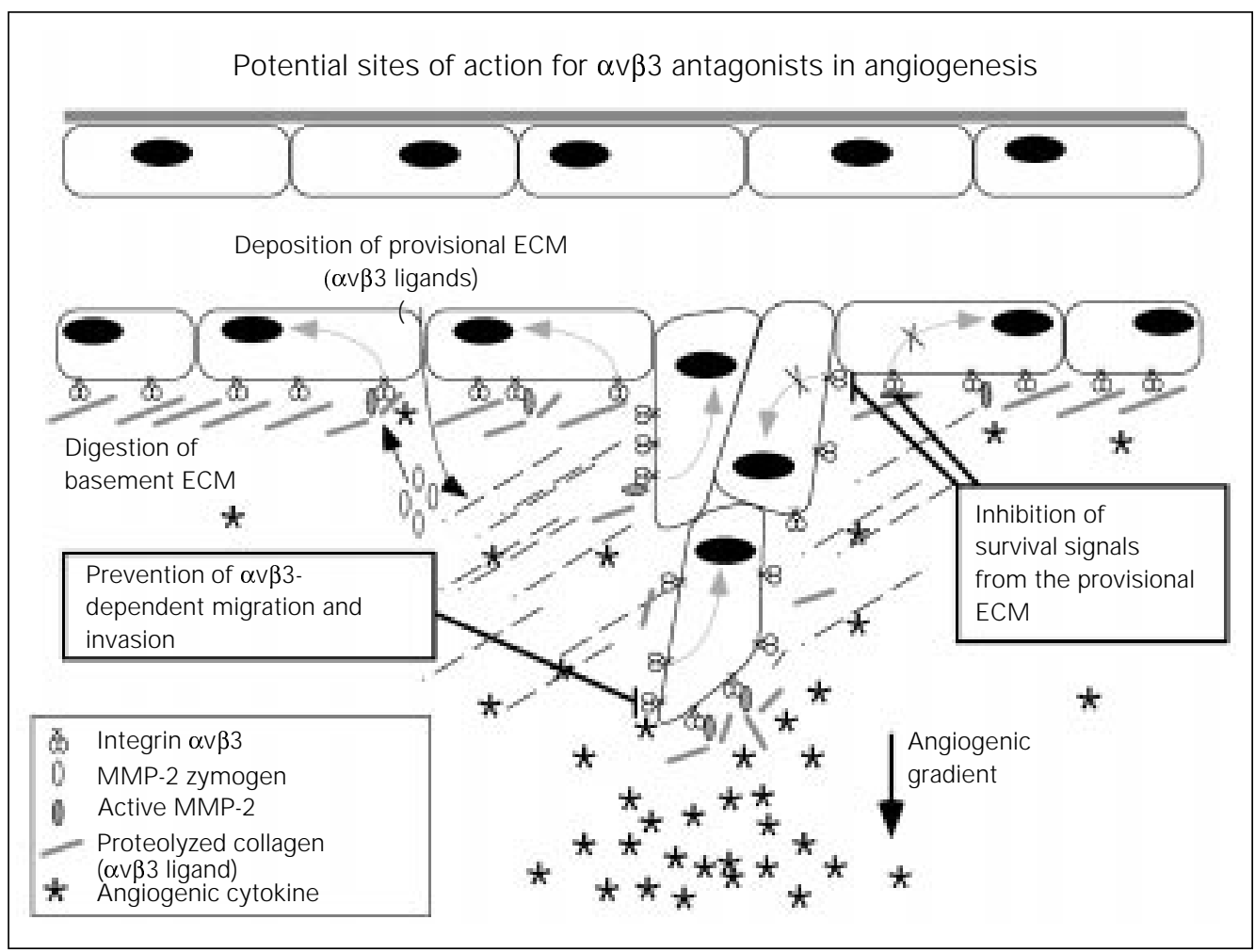


genic cytokines (35), but also induces apoptosis of angiogenic endothelial cells in vivo (45). Recent investigations have demonstrated that lack of $\alpha \mathrm{v} \beta 3$ ligation in $\alpha \mathrm{v} \beta 3$ expressing endothelial cell effects changes in p53 tumor suppressor gene activity, resulting in alterations in downstream effector expression (including $\mathrm{p} 21^{\text {cip } 1 / \text { wafl }}$ and bax) and apoptotic cell death (46). Conversely, ligation of $\alpha v \beta 3$ leads to translocation of the transcription factor NF- $\kappa B$ to the cell nucleus, promoting endothelial cell survival (47). Thus, antagonism of integrin $\alpha v \beta 3$ on endothelial cells may block angiogenic responses through complementary mechanisms, summarized in Figure 1.

Anti-angiogenic effects of $\alpha \mathrm{v} ß 3$ antagonists have been demonstrated in several in vivo models, including the chick chorio-allantoic membrane (CAM) model, where $\alpha v \beta 3$ selective antagonists inhibit both cytokine(bFGF) and tumor cell- (melanoma) induced angiogenesis $(43,46)$, and the rabbit corneal micropocket assay where bFGF-induced neovascularization is also blocked by local administration of $\alpha v \beta 3$ antagonists (48). Systemic administration of these agents inhibited neovascularization and tumor growth in nude mice (45) as well as tumor growth in human skin in a chimeric human/mouse xenograft model (49). These results support a conserved role for integrin $\alpha v B 3$ as a crucial angiogenic mediator under a variety of circumstances.

Given the role of this integrin in promoting angiogenesis and modulating endothelial cell responses, it is not surprising that the expression of $\alpha v \beta 3$ is tightly regulated. Studies within our laboratory have demonstrated that $\alpha v \beta 3$ expression is specifically induced on activated endothelial cells, and is one of several proteins coordinately induced by the Hox D3 gene program. Expression of Hox D3 results in the acquisition of an invasive phenotype in quiescent endothelial cells (24).

The invasive phenotype appears to provide a selective target for antagonist activity in vivo. Immunohistochemical examination of tumor fragments implanted in either human skin xenograft or on chick CAM revealed necrotic areas associated with reduced vascularity and obvious disruption of the tumor-associated vasculature (45). TUNEL staining revealed the presence of apoptotic blood vessels in tumor-associated vasculature, yet no apoptosis was observed in adjacent uninvolved tissues. Thus, although integrin antagonists are potent inhibitors of angiogenesis, no effect is apparent on quiescent endothelium.
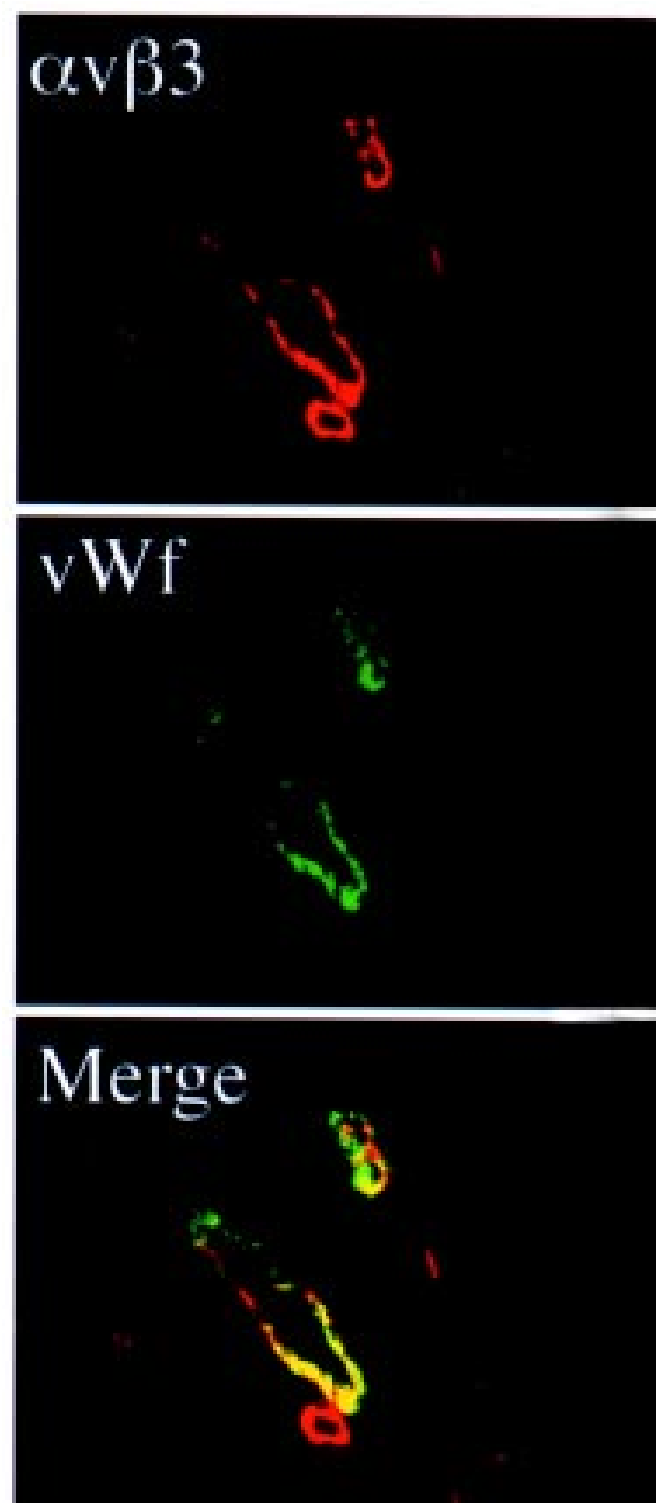

Figure 2 - The expression of integrin $\alpha$ Vß3 in rheumatoid arthritis. Cryosections of human RA synovium were stained with monoclonal antibody LM609, specific for integrin $\alpha \mathrm{V} 33$, and detected with secondary rhodamine-conjugated donkey anti-mouse ( $\alpha$ Vß3) (red). Sections were costained with goat polyclonal antisera to von Willebrand factor and detected with secondary FITC-conjugated donkey antigoat antisera (vWf) to reveal mature blood vessels (green). The colocalization of the signals is revealed when the fluorescent channels are combined (Merge, yellow) (400X). Note that many early microvessels, which do not yet stain for wWf, stain selectively for integrin $\alpha \mathrm{V} ß 3$. 


\section{Targeting integrins in arthritis}

Integrin $\alpha v \beta 3$ is highly expressed on the synovial endothelium in RA $(50,51)$, as identified by costaining for von Willebrand factor, an endothelial cell marker (Figure 2). Studies in our laboratory have revealed that integrin $\alpha v \beta 3$ is also upregulated on vascular cells in a rabbit antigen-induced arthritis (AIA) model (52). This model resembles human disease histopathologically, including neovascularization, synovial hypertrophy and subsynovial inflammatory infiltrate, and presented a unique opportunity to demonstrate specifically the impact of integrin-based anti-angiogenic therapy in arthritis.

Previously, integrin antagonists derived from fragments of the fibronectin cell-binding domain have been demonstrated to inhibit the development of arthritis in a rat model of disease (53). The activity of these peptides has been attributed to their capacity to block the activity of $\beta 1$ integrins, and therefore it was proposed that decreased arthritis resulted from the prevention of autoimmune/proinflammatory cell recruitment into the synovium. Similar peptides prevent inflammation in delayed-type hypersensitivity reactions through this mechanism (54). However, it is noteworthy that these linear peptide antagonists have broad specificity, and actually inhibit integrin $\alpha v \beta 3$-dependent adhesion at lower concentrations than, for example, integrin $\alpha 5 \beta 1$-mediated adhesion (55). This raises the possibility that some of the observed anti-arthritic activity resulted from anti-angiogenic effects. In order to address these types of questions, antagonists with higher specificity/selectivity will be required. Since the principal target of novel cyclic $\alpha v$ antagonists used in tumor studies appears to be endothelial cells expressing $\alpha v \beta 3$, these compounds may be amenable to future studies on RA (46). The success of alternative, toxin-based anti-angiogenic strategies such as taxol (14) or derivatives of the fungal metabolite fumagillin (15) validates targeting endothelial cell-mediated pathology in RA. Together, these studies provide an excellent rationale to pursue development of integrin-based anti-angiogenic strategies as a viable approach to control RA.
Figure 3 - An alternative inhibitory mechanism for angiogenesis. The protease MMP-2 is produced as a nonactive $z y$ mogen. Binding to integrin $\alpha \mathrm{V} 33$ via the noncatalytic hemopexin (PEX) domain facilitates the processing of MMP-2 to its active form, and also localizes the activity of the protease to the surface of invasive cells (left panel). An excess of the recombinant PEX domain blocks neovascularization by competitively inhibiting the binding of unactivated MMP-2 to endothelial cells, preventing activation of proteolytic activity (right panel).

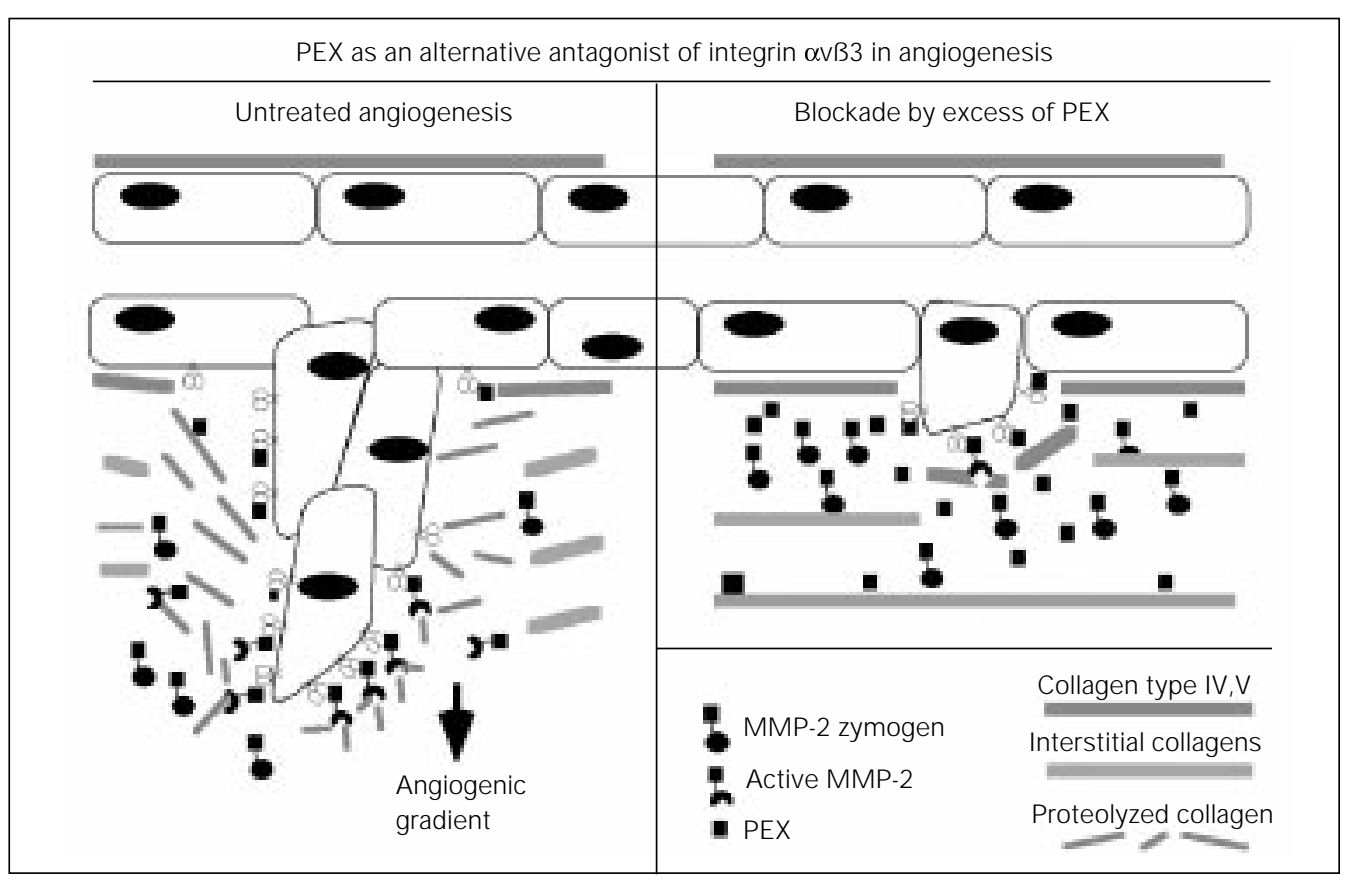




\section{Incorporated themes in future anti- angiogenic strategies}

Since cellular responses to cytokines and other soluble factors occur within the governing context of the ECM, modulation of these responses through the antagonism of adhesion receptors is becoming increasingly attractive as a therapy. Increased efficacy may be achieved by alternative approaches, including systemic administration of stable antagonists or possibly local gene delivery allowing regional production of anti-angiogenic proteins for extended periods. Angiogenesis is influenced by an ever-growing list of proteins, protein fragments, peptides, sugars and lipids, but a common element in the angiogenic response induced by any means is the local reorganization of the ECM. Toward this end, a second strategy developed for the control of angiogenesis combines antagonism of $\alpha v \beta 3$ with prevention of ECM alteration. The recent discovery that integrin $\alpha v \beta 3$ binding to MMP- 2 is mediated via the hemopexin domain of MMP-2 (PEX) (56) has led to the development of recombinant PEX as a coordinate inhibitor of integrin function and MMP-2 activation in vitro. As might be predicted from these results, PEX also blocks angiogenesis in vivo (Figure 3) (56), suggesting that future identification of key sequences in PEX may provide additional multifunctional angiogenesis inhibitors.

Enhanced control of angiogenic responses may be possible by coordinately inhibiting complementary potentiating events involved in neovascularization. In the case of RA, the ongoing inflammatory component presents an obvious and important target (57), since angiogenesis and inflammation are complementary events contributing to disease progression. This type of "logical" combination therapy, in which both ongoing neovascularization and inflammation are targeted as distinct but inter-related components, may offer the most effective means of treatment for rheumatoid arthritis. Recent studies focusing on the interactions of cells with the ECM have led to advances in both angiogenesis and inflammation research, providing valuable tools for future investigations. Ultimately, an increased understanding of the pathological mechanisms in RA will permit development of new and innovative therapies.

\section{References}

1. Pincus T (1995). The underestimated long term medical and economic consequences of rheumatoid arthritis. Drugs, 50 (Suppl 1): 1-14.

2. McCabe CJ (1997). Health economics in rheumatology. Baillieres Clinical Rheumatology, 11: 145-156.

3. Zvaifler NJ \& Firestein GS (1994). Pannus and pannocytes. Alternative models of joint destruction in rheumatoid arthritis. Arthritis and Rheumatism, 37: 783-789.

4. Shiozawa S \& Tokuhisa T (1992). Contribution of synovial mesenchymal cells to the pathogenesis of rheumatoid arthritis. Seminars in Arthritis and Rheumatology, 21: 267-273.

5. Kimball ES \& Gross J L (1991). Angiogenesis in pannus formation. Agents and ACtions, 34: 329-331.
6. Colville-Nash PR \& Scott DL (1992). Angiogenesis and rheumatoid arthritis: pathogenic and therapeutic implications. Annals of the Rheumatic Diseases, 51: 919925.

7. Koch AE (1998). Angiogenesis: implications for rheumatoid arthritis. Arthritis and Rheumatism, 41: 951-962.

8. Matsubara T \& Ziff M (1987). Inhibition of endothelial cell proliferation by gold compounds. J ournal of Clinical Investigation, 79: 1440-1446.

9. Madhok R, Wijelath E, Smith J , Watson J , Sturrock RD \& Capell HA (1991). Is the beneficial effect of sulfasalazine due to inhibition of synovial neovascularization? J ournal of Rheumatology, 18: 199-202.

10. Potvin F, Petitclerc E, Marceau F \& Poubelle PE (1997). Mechanisms of ac- tion of antimalarials in inflammation: induction of apoptosis in human endothelial cells. J ournal of Immunology, 158: 18721879.

11. Hirata S, Matsubara T, Saura R, Tateishi H $\&$ Hirohata K (1989). Inhibition of in vitro vascular endothelial cell proliferation and in vivo neovascularization by low dose methotrexate. Arthritis and Rheumatism, 32: 1065-1073.

12. Matsubara T, Saura R, Hirohata K \& Ziff M (1989). Inhibition of human endothelial cell proliferation in vitro and neovascularization in vivo by D-penicillamine. J ournal of Clinical Investigation, 83: 158-167.

13. Tsujii M, Kawano S, Tsuji S, Sawaoka H, Hori M \& DuBois RN (1998). Cyclooxygenase regulates angiogenesis induced by colon cancer cells. Cell, 93: 705-716. 
14. Peacock DJ, Banquerigo $M L \&$ Brahn $E$ (1995). A novel angiogenesis inhibitor suppresses rat adjuvant arthritis. Cellular Immunology, 160: 178-184.

15. Oliver SJ, Banquerigo $\mathrm{ML} \&$ Brahn E (1994). Suppression of collagen-induced arthritis using an angiogenesis inhibitor, AGM 1470, and a microtubule stabilizer, Taxol. Cellular Immunology, 157: 291-299.

16. Folkman J (1995). Angiogenesis in cancer, vascular, rheumatoid and other disease. Nature Medicine, 1: 27-31.

17. Muller-Ladner U, Kriegsmann J, Gay RE \& Gay S (1995). Oncogenes in rheumatoid arthritis. Rheumatic Diseases Clinics of North America, 21: 675-690.

18. Walsh DA, Wade M, Mapp PI \& Blake DR (1998). Focally regulated endothelial proliferation and cell death in human synovium. American J oumal of Pathology, 152: 691-702.

19. Varani J , Mulligan MS \& Ward PA (1994). The vascular endothelium and acute inflammation. In: Klippel JH \& Dieppe PA (Editors), Rheumatology. Mosby, St Louis.

20. Gualandris A, Rusnati $M$, Belleri $M$, Nelli EE, Bastaki M, Molinari-Tosatti MP, Bonardi F, Parolini S, Albini A, Morbidelli L, Ziche M, Corallini A, Possati L, Vacca A, Ribatti D \& Presta M (1996). Basic fibroblast growth factor overexpression in endothelial cells: an autocrine mechanism for angiogenesis and angioproliferative diseases. Cell Growth and Differentiation, 7: 147-160.

21. Barleon B, Sozzani S, Zhou D, Weich HA, Mantovani A \& Marme D (1996). Migration of human monocytes in response to vascular endothelial growth factor (VEGF) is mediated via the VEGF receptor flt-1. Blood, 87: 3336-3343.

22. Eguchi K, Migita $K$, Nakashima M, Ida $H$, Terada K, Sakai M, Kawakami A, Aoyagi T, Ishimaru T \& Nagataki S (1992). Fibroblast growth factors released by wounded endothelial cells stimulate proliferation of synovial cells. Rheumatology, 19: 19251932.

23. Mignatti P \& Rifkin DB (1996). Plasminogen activators and matrix metalloproteinases in angiogenesis. Enzymes and Proteins, 49: 117-137.

24. Ziats NP \& Anderson J M (1993). Human vascular endothelial cell attachment and growth inhibition by type $V$ collagen. J ournal of Vascular Surgery, 17: 710-718.

25. Boudreau N, Andrews C, Srebrow A, Ravanpay A \& Cheresh DA (1997). Regulation of the angiogenic phenotype by Hox D3. J ournal of Cell Biology, 139: 257-264.

26. Meredith J r J E, Fazeli B \& Schwartz MA
(1993). The extracellular matrix as a cell survival factor. Molecular Biology of the Cell, 4: 953-961.

27. Cornelius LA, Nehring LC, Roby J D, Parks WC \& Welgus HG (1995). Human dermal microvascular endothelial cells produce matrix metalloproteinases in response to angiogenic factors and migration. J ournal of Investigative Dermatology, 105: 170176.

28. Dvorak HF, Brown LF, Detmar M \& Dvorak AM (1995). Vascular permeability factor/vascular endothelial growth factor, microvascular hyperpermeability, and angiogenesis. American J ournal of Pathology, 146: 1029-1039.

29. Reininger $A J$, Heinzmann $U$, Reininger CB, Friedrich P \& Wurzinger LJ (1994). Flow mediated fibrin thrombus formation in an endothelium-lined model of arterial branching. Thrombosis Research, 74: 629641.

30. Postigo AA, Garcia-Vicuna R, Laffon A \& Sanchez-Madrid $F$ (1993). The role of adhesion molecules in the pathogenesis of rheumatoid arthritis. Autoimmunity, 16: 69-76.

31. Busso N, Peclat V, Van Ness K, Kolodziesczyk E, Degen J , Bugge T \& So A (1998). Exacerbation of antigen-induced arthritis in urokinase-deficient mice. J ournal of Clinical Investigation, 102: 41-50.

32. Leavesley DI, Schwartz MA, Rosenfeld M \& Cheresh DA (1990). Integrin ß1- and ß3mediated endothelial cell migration is triggered through distinct signaling mechanisms. J ournal of Cell Biology, 121: 163170.

33. Lampugnani MG, Giorgi M, Gaboli M, Dejana E \& Marchisio PC (1990). Endothelial cell motility, integrin receptor clustering, and microfilament organization are inhibited by agents that increase intracellular CAMP. Laboratory Investigation, 63: 521-531.

34. Bull DA, Seftor EA, Hendrix MJ, Larson DF, Hunter GC \& Putnam CW (1993). Putative vascular endothelial cell chemotactic factors: comparison in a standardized migration assay. J ournal of Surgical Research, 55: 473-479.

35. Saiki I, Murata J, Makabe T, Nishi N, Tokura S \& Azuma I (1990). Inhibition of tumor angiogenesis by a synthetic celladhesive polypeptide containing the ArgGly-Asp (RGD) sequence of fibronectin, poly(RGD). J apanese J ournal of Cancer Research, 81: 668-675.

36. Aplin $A E$, Howe $A$, Alahari $S K \&$ J uliano RL (1998). Signal transduction and signal modulation by cell adhesion receptors: the role of integrins, cadherins, immunoglobulin-cell adhesion molecules and selectins. Pharmacological Reviews, 50: 197-263.

37. Shimizu $Y \&$ Shaw S (1991). Lymphocyte interactions with extracellular matrix. FASEB J ournal, 5: 2292-2299.

38. Gillis S, Furie BC \& Furie B (1997). Interactions of neutrophils and coagulation proteins. Seminars in Hematology, 34: 336342.

39. Simms H \& D'Amica R (1994). Matrix protein regulation of PMN oxidative metabolism during ischemia. American J ournal of Physiology, 266: C637-C647.

40. Eliceiri BP, Strömblad S, Klemke R \& Cheresh DA (1998). Integrin requirement for sustained MAP kinase activity during angiogenesis. J ournal of Cell Biology, 140: 1255-1263.

41. Short SM, Talbott GA \& J uliano RL (1998). Integrin-mediated signaling events in human endothelial cells. Molecular Biology of the Cell, 9: 1969-1980.

42. Brooks PC, Clark RA \& Cheresh DA (1994). Requirement of vascular integrin aVß3 for angiogenesis. Science, 264: 569571.

43. Varner J A, Brooks PC \& Cheresh DA (1995). The integrin $\alpha \mathrm{Vß3}$ : Angiogenesis and apoptosis. Cell Adhesion and Communication, 3: 367-374.

44. Brooks PC, Stromblad S, Sanders LC, von Schalscha T, Aimes RT, Stetler-Stevenson WG, Quigley JP \& Cheresh DA (1996). Localization of matrix metalloproteinase MMP-2 to the surface of invasive cells by interaction with integrin $\alpha$ Vß3. Cell, 85: 120.

45. Brooks PC, Montgomery AMP, Rosenfeld $M$, Reisfeld RA, Hu T, Klier G \& Cheresh DA (1994). Integrin $\alpha$ Vß3 antagonists promote tumor regression by inducing apoptosis of angiogenic blood vessels. Cell, 79: 1157-1164.

46. Strömblad S, Becker J C, Yebra M, Brooks PC \& Cheresh DA (1996). Suppression of p53 and p21WAF1/CIP1 expression by vascular cell integrin $\alpha \mathrm{V} ß 3$ during angiogenesis in vivo. J ournal of Clinical Investigation, 98: 426-433.

47. Scatena $M$, Almeida $M L$, Fausto $N$, Nicosia RE \& Giachelli CM (1998). NF-kB mediates $\alpha V B 3$ integrin-induced endothelial cell survival. J ournal of Cell Biology, 141: 1083-1093.

48. Friedlander M, Brooks PC, Shaffer RW, Kincaid CM, Varner JA \& Cheresh DA (1995). Definition of two angiogenic pathways by distinct $\alpha v$ integrins. Science, 270: 1500-1502. 
49. Brooks PC, Strömblad S, Klemke R, Visscher D, Sarkar FH \& Cheresh DA (1995). Anti-integrin $\alpha$ Vß3 blocks human breast cancer growth and angiogenesis in human skin. J ournal of Clinical Investigation, 96: 1815-1822.

50. J ohnson BA, Haines GK, Harlow LA \& Kock AE (1993). Adhesion molecule expression in human synovial tissue. Arthritis and Rheumatism, 36: 137-146.

51. Nikkari L, Haapasalmi $K$, Aho $H$, Torvinen A, Sheppard D, Larjava $H$ \& Heino J (1995). Localization of the $\alpha v$ subfamily of integrins and their putative ligands in synovial lining cell layer. J ournal of Rheumatology, 22: 16-23.

52. Storgard CM, Stupack DG, J onczyk A, Goodman SL, Fox RI \& Cheresh DA (1999). Decreased angiogenesis and arthritic disease in rabbits treated with an $\alpha \mathrm{Vß3}$ antagonist. J ournal of Clinical Investigation, 103: 1-8.

53. Wahl SM, Allen J B, Hines KL, Imamichi $T$, Wahl AM, Furcht LT \& McCarthy JB (1994). Synthetic fibronectin peptides suppress arthritis in rats by interrupting leukocyte adhesion and recruitment. J ournal of Clinical Investigation, 94: 655-662.

54. Hershkoviz R, Greenspoon N, Mekori YA, Hadari R, Alon R, Kapustina G \& Lider O (1994). Inhibition of CD4+ T lymphocyte binding to fibronectin and immune-cell accumulation in inflammatory sites by non-peptidic mimetics of Arg-Gly-Asp. Clinical and Experimental Immunology, 95: 270-276.

55. Pfaff M, Tangemann K, Muller B, Gurrath M, Muller G, Kessler H, Timpl R \& Engel J (1994). Selective recognition of cyclic RGD peptides of NMR defined conformation by $\alpha \| ß ß 3, \alpha v ß 3$, and $\alpha 5 \beta 1$ integrins. J ournal of Biological Chemistry, 2692: 20233-20238.

56. Brooks PC, Silletti $S$, von Schalscha TL, Friedlander M \& Cheresh DA (1998). Disruption of angiogenesis by PEX, a noncatalytic metalloproteinase fragment with integrin binding activity. Cell, 92: 391-400.

57. Paleolog E (1997). Target effector role of vascular endothelium in the inflammatory response: insights from the clinical trial of anti-TNFalpha antibody in rheumatoid ar- thritis. Molecular Pathology, 50: 225-233.

58. Sunderkotter $C$, Steinbrink $K$, Goebeler M, Bhardwaj R \& Sorg C (1994). Macrophages and angiogenesis. J ournal of Leukocyte Biology, 55: 410-422.

59. J ackson J R, Minton J A, Ho ML, Wei N \& Winkler J D (1997). Expression of vascular endothelial growth factor in synovial fibroblasts is induced by hypoxia and interleukin 1 beta. J ournal of Rheumatology, 24: 1253-1259.

60. Ruegg C, Yilmaz A, Bieler G, Bamat J, Chaubert P \& Lejeune FJ (1998). Evidence for the involvement of endothelial cell integrin $\alpha \mathrm{V} ß 3$ in the disruption of the tumor vasculature induced by TNF and IFN$\gamma$. Nature Medicine, 4: 408-414.

61. Koch AE, Halloran MM, Hosaka S, Shah MR, Haskell CJ, Baker SK, Panos RJ, Haines GK, Bennett GL, Pope RM \& Ferrara N (1996). Hepatocyte growth factor. A cytokine mediating endothelial migration in inflammatory arthritis. Arthritis and Rheumatism, 39: 1566-1575. 